\title{
Estudio preliminar del proceso de producción de cerveza a partir de sorgo rojo CIAP R-132 a escala de laboratorio
}

\author{
Preliminary study of the beer production process from red sorghum \\ CIAP R-132 at laboratory scale
}

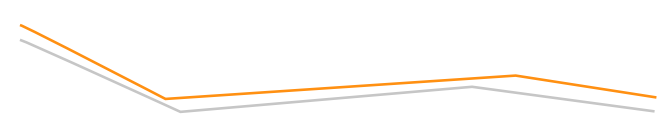

Amaury Pérez-Sánchez*凶, Helen María Alfonso-Fernández*, Julio César Aragón-Fontes*, José Gerardo Baltá-García*, Isnel Benítez-Cortés*

Pérez-Sánchez, A., Alfonso-Fernández, H. M., Aragón-Fontes, J. C., Baltá-García, J. G., \& Benítez-Cortés, I. (2019). Estudio preliminar del proceso de producción de cerveza a partir de sorgo rojo CIAP R-132 a escala de laboratorio. Investigación y Ciencia de la Universidad Autónoma de Aguascalientes, 27(77), 27-37.

\section{RESUMEN}

Se realizó un estudio preliminar del proceso de producción de cerveza a partir de sorgo rojo CIAP R-132 a escala de laboratorio. Se obtuvo una germinación promedio de $75.15 \%$, mientras que la cerveza obtenida tuvo un valor promedio de alcohol de $1.28 \%$, de extracto original igual a $3.68 \%$, y acidez de $4.26 \%$. Se realizó una prueba a escala de banco, efectuando la etapa de cocción y agregando lúpulo durante la misma, obteniéndose un porcentaje de alcohol de $0.56 \%$, extracto original igual a $3.46 \%$ y acidez de $1.29 \%$. A partir de las conclusiones del estudio se recomienda realizar la etapa de remojo en solución de $\mathrm{NaOH} 0.1 \% \mathrm{~m} / \mathrm{m}$, llevar a cabo la etapa de cocción en el proceso productivo, añadir sacarosa o compuestos ricos en azúcares fermentables al mosto antes de la fermentación, y agregar la enzima exógena Fungamyl 800 I durante el proceso de maceración.

Palabras clave: sorgo rojo CIAP R-132; cerveza; malteado; maceración; fermentación.

Keywords: red sorghum CIAP R-132; beer; malting; maceration; fermentation.

Recibido: 14 de julio de 2018, aceptado: 8 de febrero de 2019

* Facultad de Ciencias Aplicadas, Universidad de Camagüey "Ignacio Agramonte Loynaz". Carretera Circunvalación Norte, $\mathrm{km} \mathrm{51/2,} \mathrm{e/Camino}$ Viejo de Nuevitas y Ave. Ignacio Agramonte, C. P. 74650, Camagüey, Cuba. Correo electrónico: amauryps@nauta.cu; helen.alfonso@reduc. edu.cu; julio.aragon@reduc.edu.cu; gerardo.balta@reduc.edu.cu; isnel.benites@reduc.edu.cu. ORCID: http://orcid.org/0000-0002-08196760; http://orcid.org/0000-0002-8785-8899; http://orcid.org/00000003-0511-232X; http://orcid.org/0000-0002-6768-1272; http://orcid. org/0000-0003-2427-640X

凶

Autor para correspondencia
We made a preliminary study of the beer production process from red sorghum CIAP R-132 at laboratory scale. The obtained results show an average germination value of $75.15 \%$, while the beer obtained had an average alcoholic percentage value of $1.28 \%$, an original extract value equal to $3.68 \%$ and acidity percentage of $4.26 \%$. We did a bench-scale test, implementing the cooking stage and adding hop during it, hence obtaining $0.56 \%$ of alcoholic percentage; $3.46 \%$ of original extract; and $1.29 \%$ of acidity. From the conclusions obtained for this study it's recommended to do the steeping stage with a $0.1 \% \mathrm{w} / \mathrm{w} \mathrm{NaOH}$ aqueous solution, to carry out the cooking stage in the production process, to add sucrose or sugar-rich compounds to the wort prior to fermentation, and to add Fungamyl 800 I exogenous enzyme during maceration process.

\section{INTRODUCCIÓN}

El sorgo (sorghum bicolor L. Moench) es, en términos de producción mundial, la quinta gramínea después del trigo, arroz, maíz y avena (Ortega Díaz, 2016), los mayores productores a nivel mundial son Estados Unidos, 25\%; India, 21.5\%; Nigeria, 6.9\%; México, 10.7\%; Argentina, 3.5\% (Bernal Negrete, Pérez Rodríguez, \& Delgado Morales, 2015). Es un cultivo que tiene alta tolerancia a la sequía y se adapta a zonas tropicales y subtropicales. Puede ser empleado para la producción de panes y cereales para el desayuno, en obtención de bioetanol, jarabes de glucosa o fructosa y como componente (tanto principal como adjunto) en la producción de cerveza. 
issn 1665-4412, e-issn 2521-9758

Pérez-Sánchez, A., Alfonso-Fernández, H. M., Aragón-Fontes, J. C.,

28

Según Gallardo Aguilar et al. (2013, p. 63), la cerveza es una "expresión genérica para designar a la bebida resultante de fermentar, mediante levadura seleccionada, el mosto procedente de la malta de granos de cereal, solo o mezclado con otros adjuntos cerveceros transformables en azúcares por digestión enzimática, la que es sometida previamente a un proceso de cocción y aromatizados sus extractos y/o sus concentrados con flores de lúpulo. Su graduación alcohólica no será inferior al $3 \%$ en masa y el extracto seco primitivo (ESP) no será inferior al $11 \%$ en masa".

La producción de cerveza mediante el uso de $100 \%$ en grano de sorgo es un concepto relativamente nuevo (Ratnavathi, \& Chavan, 2016), donde el continente africano es una de las regiones donde más se emplea el sorgo de forma tradicional para la obtención de bebidas alimenticias fermentadas, tanto alcohólicas como no alcohólicas (Lyumugabe, Gros, Nzugize, Baiyana, \& Thorant, 2012; Ramatoulaye et al., 2016). Aquellos cultivos que presentan una baja temperatura de gelatinización, baja cantidad de polipéptidos y lípidos, alto poder diastático y proteínas fácilmente solubles son excelentes para la preparación de cervezas (Ratnavathi \& Chavan, 2016).

Las cervezas obtenidas a partir de sorgo son ricas en vitaminas del complejo B, lo que incluye tiamina, ácido fólico, riboflavina y ácido nicotínico; estas presentan gran cantidad de minerales como hierro, fósforo y potasio, y alto contenido de aminoácidos esenciales como la lisina (Lyumugabe et al., 2012). También diferentes productos alimenticios y bebidas obtenidas a partir del sorgo pueden ser consumidos por personas con enfermedad celíaca debido a que no contienen gluten.

En Cuba la variedad de sorgo más cultivada es el sorgo blanco UDG-110, la cual se emplea fundamentalmente como sustituto de la harina de trigo o cebada para la elaboración de pan, galletas, bizcochos, dulces y bebidas (Chaviano Marañón, 2005). También se cultiva el sorgo rojo CIAP R-132, el cual presenta potencialidades prometedoras que aún no han sido explotadas al máximo, principalmente para la producción de bebidas y productos alimenticios (Nieblas Morfa et al., 2016).

En los últimos años en Cuba se ha evaluado el empleo de diversas variedades de sorgo para la producción de cerveza y maltinas, de forma integral o como adjunto, también se han efectuado estudios relacionados con diversos procesos químicos. De esta manera, Rodríguez Rodríguez, Gallardo Aguilar, Nieblas Morfa y Ortiz Fernández (2015b) evaluaron el proceso de molienda húmeda para la extracción de almidón, tomando en cuenta dos variedades de sorgo: rojo (CIAP R-132) y blanco (UDG-110). Por su parte, Rodríguez Rodríguez, Gallardo Aguilar, Nieblas Morfa, Medina Macola y Ortiz Fernández (2015a) estudiaron el proceso de producción de jarabe dextrinizado mediante la hidrólisis enzimática del almidón de sorgo rojo CIAP R-132 y a partir del empleo de la enzima $\alpha$-amilasa, con lo que se han obtenido jarabes dextrinizados con valores de equivalente de dextrosa (ED) entre 10.25 y $33.97 \%$.

Nieblas Morfa et al. (2016) elaboraron cerveza combinando sorgo malteado (blanco UDG-110 y rojo CIAP R-132) con cebada malteada, además de producir maltina a escala piloto utilizando íntegramente sorgo malteado. También optimizaron la etapa de malteado, tanto del sorgo blanco UDG110 como del rojo CIAP R-132. Gallardo Aguilar et al. (2013) abordaron el estudio de la obtención de dos bebidas, maltina y cerveza, a partir de sorgo blanco UDG-110 malteado, obteniendo resultados satisfactorios. Carvajal (2014) estudió el proceso de producción de cerveza a partir de sorgo blanco UDG-110 a escala de laboratorio, con el objetivo de evaluar la influencia de distintas variables sobre dos etapas del proceso productivo: malteado y fermentación.

Díaz Rodríguez (2014) estudió la elaboración de maltina a partir de sorgo blanco UDG-110, optimizado el proceso de malteado a partir del estudio de las variables que más influyen en el mismo, tales como concentración de $\mathrm{NaOH}$, tiempo de remojo y germinación. Por último, Ortega Díaz (2016) llevó a cabo la producción de cerveza utilizando íntegramente sorgo blanco UDG-110, tanto malteado como en forma de jarabe, a escala de laboratorio.

Sin embargo, hasta la fecha no se ha reportado el uso integral de sorgo rojo CIAP R-132 para obtener cerveza en Cuba, por lo que en el siguiente trabajo se realiza un estudio del proceso de obtención de cerveza a partir de esta variedad de sorgo, con el fin de estudiar de forma preliminar cada una de las etapas involucradas en el proceso productivo, y definir los parámetros de operación más importantes, tomando en cuenta diferentes alternativas de remojo 
y la adición o no de la enzima exógena Fungamyl 800 I durante la etapa de maceración.

\section{MATERIALES Y MÉTODOS}

\section{Descripción del proceso de producción de cerveza a partir de sorgo rojo CIAP R-132}

El proceso de producción de cerveza utilizando sorgo rojo CIAP R-132 como materia prima principal contó con las siguientes etapas principales (Bernal Negrete et al., 2015; Carvajal, 2014; Lyumugabe et al., 2012; Ortega Díaz, 2016):

1) Clasificación de los granos

2) remojo

3) germinación

4) secado

5) tamizado

6) molienda

7) maceración

8) filtración y lavado

9) fermentación

10) filtración secundaria y envasado (figura 1).

Clasificación de los granos. Se efectuó limpieza y clasificación primaria de los granos de sorgo, mediante la cual se escogen y desechan granos fracturados, dañados y/o fragmentados, materias extrañas como pajillas, piedras y partículas extrañas. Se empleó para ello un tamiz o colador de metal.

Remojo. Se pesaron $500 \mathrm{~g}$ de sorgo rojo CIAP R-132 en una balanza técnica (ScalTec ${ }^{\circledR}$ Modelo SPB 63) y se distribuyeron en 10 placas Petri de cristal a razón de $50 \mathrm{~g}$ por placa. A continuación las mismas fueron puestas en remojo tomando en cuenta dos variantes de estudio:

- Variante 1: Remojo en agua pura. Se tomaron cinco placas y se les agregaron $150 \mathrm{ml}$ de agua por placa hasta cubrir totalmente los granos. Las placas se dejaron en remojo por $48 \mathrm{~h}$ a temperatura ambiente $\left(\sim 25^{\circ} \mathrm{C}\right)$, y cada 12 horas se les cambió el agua.

- Variante 2: Remojo en una solución acuosa de $\mathrm{NaOH} 0.1 \% \mathrm{~m} / \mathrm{m}$. Se tomaron cinco placas y se les agregaron $150 \mathrm{ml}$ de la solución acuosa de $\mathrm{NaOH} 0.1 \% \mathrm{~m} / \mathrm{m}$ por placa hasta cubrir totalmente los granos. Las placas se dejaron en remojo por $12 \mathrm{~h}$ a temperatura ambiente $(\sim 25$ ${ }^{\circ} \mathrm{C}$ ) (Carvajal, 2014; Ortega Díaz, 2016). Cada 6 h se les cambió la solución.

Al concluir el tiempo de remojo se determinó la humedad alcanzada por los granos.

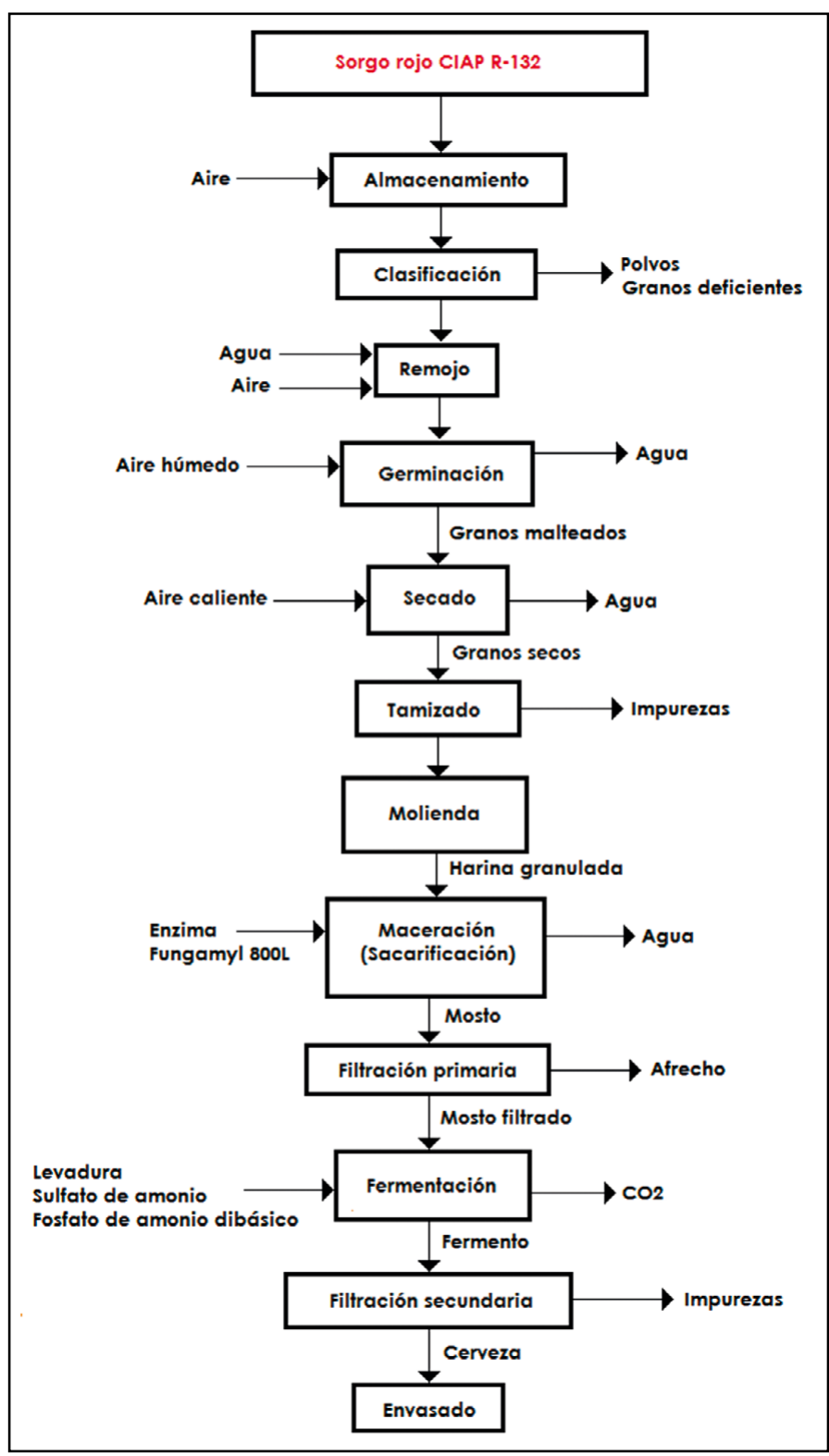

Figura 1. Diagrama de bloques del proceso de producción de cerveza a partir de sorgo rojo CIAP R-132.

Elaboración propia.

Germinación. Una vez cumplido el tiempo de remojo se le retiró tanto el agua como la solución de $\mathrm{NaOH}$ a cada una de las placas en dependencia de la variante considerada. A continuación, las placas fueron cubiertas con paños húmedos y se introdujeron en el interior de un horno (Huandong Machinery ${ }^{\circledR}$ 101-3) operando a una temperatura entre 25 y $30^{\circ} \mathrm{C}$ y una humedad relativa entre 92 y $98 \%$. Las placas fueron rociadas dos veces al día con el fin de mantener la humedad alcanzada en la etapa de remojo. Se tomó en cuenta un tiempo de 
issn 1665-4412, e-issn 2521-9758

Pérez-Sánchez, A., Alfonso-Fernández,

H. M., Aragón-Fontes, J. C.,

30

Baltá-García, J. G., \& Benítez-Cortés, I. germinación de $72 \mathrm{~h}$ para cada variante (Carvajal, 2014; Díaz Rodríguez, 2014; Ortega Díaz, 2016), se observó el brote de raicillas o plumillas en los granos al finalizar el tiempo de germinación.

Terminado el tiempo de germinación se procedió a determinar el porcentaje de este (\% Ger) a partir del conteo de los granos germinados y los no germinados existentes en al menos dos placas por variante. El \% Ger se determinó mediante la siguiente ecuación:

$$
\% \text { Ger }=\frac{\text { Granos germinados }}{\text { Granos totales }} \times 100
$$

Secado. El sorgo germinado contenido en las cinco placas utilizadas en la variante 1 fue esparcido en una bandeja metálica, mientras que el de las cinco placas empleadas en la variante 2 fue dispersado en una segunda bandeja metálica, tomando precaución de que los granos estuvieran distribuidos uniformemente y formaran una sola capa. Posteriormente, las dos bandejas fueron introducidas en un horno de tiro inducido (Huandong Machinery ${ }^{\circledR}$ 101-3) y se efectuó el secado a $60^{\circ} \mathrm{C}$ con el fin de garantizar la no destrucción de las enzimas producidas y evitar la vitrificación del grano. Se tomaron muestras cada 30 min para determinar el porcentaje de humedad de los granos. El secado se detuvo cuando los mismos alcanzaron una humedad menor a 5\% (Carvajal, 2014; Ortega Díaz, 2016).

Tamizado. Se procedió a retirar de forma manual y mediante un tamiz metálico, las raicillas producidas durante la germinación. Esta operación debe realizarse justo cuando termine el proceso de secado, ya que las raicillas son fuertemente higroscópicas y es más cómodo retirarlas secas (Ortega Díaz, 2016).

Molienda. Los granos malteados de sorgo sin raicillas fueron molidos en un molino de disco hasta obtener una consistencia de harina granulada, con el fin de favorecer la sacarificación del almidón durante el proceso de maceración.

Maceración. Se realiza para lograr la conversión de los almidones contenidos en el sorgo en azúcares fermentables (sacarificación). Se comenzó agregando 1.7 I de agua en un recipiente de cristal de 2.2 I de capacidad. A continuación, el recipiente fue colocado dentro de un termostato o Baño María (Bun$\operatorname{sen}^{\circledR}$ ) con el objetivo de controlar la temperatura de maceración. Tanto el pH como la temperatura del proceso de maceración fueron registrados median- te un medidor de $\mathrm{pH}$ (PHSJ-4A) con sensores para medir ambas variables.

Durante el proceso de maceración se establecieron cuatro pausas o escalones de temperaturas (Carvajal, 2014; Ortega Díaz, 2016). Primeramente, se calentó el agua contenida dentro del beaker hasta una temperatura de $38^{\circ} \mathrm{C}$, a partir de la cual se le agregó el grano de sorgo rojo en una relación sólido/líquido (sorgo/agua) de 125 $\mathrm{g} / \mathrm{l}$. Esta temperatura se mantuvo durante $40 \mathrm{~min}$. Posteriormente se incrementó la temperatura de la mezcla hasta $52^{\circ} \mathrm{C}$ y se mantuvo en este valor también durante $40 \mathrm{~min}$. En este valor de temperatura se estudiaron dos variantes en las cuales se agrega o no la enzima exógena Fungamyl 800 I (Novozymes ${ }^{\circledast}$ ) a una concentración de $0.1 \mathrm{~g} / \mathrm{l}$ de mosto. Transcurrido este tiempo se incrementó la temperatura del mosto hasta $63^{\circ} \mathrm{C}$ y se conservó en este valor durante $40 \mathrm{~min}$. Por último, se realizó un incremento de la temperatura hasta $71{ }^{\circ} \mathrm{C}$ y permaneció en este valor durante $30 \mathrm{~min}$. Todo el proceso de maceración se efectuó a una velocidad de agitación de 250 r. p.m. mediante un agitador eléctrico (Stuart Scientific ${ }^{\circledR}$ SS10).

Filtración y lavado. Se separó el líquido (mosto) del sólido (afrecho) con un colador metálico, el mosto filtrado se almacenó en un recipiente de cristal. La torta de afrecho acumulada en el colador se lavó con agua a $76 \pm 2{ }^{\circ} \mathrm{C}$, con el fin de que continuaran disolviéndose los azúcares contenidos en esta mezcla sólida (Ortega Díaz, 2016). El líquido de lavado se recogió en el mismo recipiente donde se colectó el mosto durante el primer filtrado. El afrecho agotado se desechó, mientras que el mosto contenido en el recipiente de cristal se enfrió hasta temperatura ambiente en una cuba preparada para el efecto conteniendo agua fría. Una vez enfriado, al mosto se le aplicó la prueba del yodo con el fin de comprobar si existió sacarificación del almidón durante el proceso de maceración, esto es, si el almidón se desdobló en azúcares simples. Al mosto filtrado y enfriado también se le midió el valor de los sólidos solubles totales o grados Brix ( ${ }^{\circ} \mathrm{Bx}$ ), y el $\mathrm{pH}$.

Fermentación. Al mosto previamente enfriado se le agregó $1 \mathrm{~g} / \mathrm{l}$ de sulfato de amonio y fosfato de amonio dibásico como nutrientes, y se le ajustó el $\mathrm{pH}$ hasta un rango de $5.0 \pm 2$ (Ortega Díaz, 2016). Se utilizó levadura Saccharomyces cerevisiae instantánea liofilizada (Lievito Combattenti®) como microorganismo para efectuar la fermentación 
alcohólica. La fermentación se llevó a cabo en recipientes de cristal de 5 । de volumen total (fermentadores) equipados con una trampa de gases (air-lock). La muestra por fermentar se aireó inicialmente $20 \mathrm{~min}$ con una bomba peristáltica acoplada al fermentador, con el objetivo de que la levadura adquiriera una provisión inicial de oxígeno a partir de la cual pueda crecer y multiplicarse de forma adecuada.

Filtración secundaria y envasado. El líquido obtenido al terminar la fermentación se calentó hasta temperaturas superiores a $50{ }^{\circ} \mathrm{C}$ mediante una hornilla eléctrica, con el fin de detener la actividad fermentativa de la levadura (Ortega Díaz, 2016). La mezcla se filtró mediante una tela previamente esterilizada que separó la levadura, sedimentos y otras deposiciones sólidas del líquido, este último (cerveza) se depositó en envases de plástico de 500 $\mathrm{ml}$.

\section{Diseño metodológico}

Se elaboró un diseño metodológico consistente en ocho corridas experimentales distribuidas en un experimento original y una réplica (figura 2 ), en donde se tomaron en cuenta los dos métodos de remojo anteriormente descritos (con agua y con solución de $\mathrm{NaOH}$ ), así como también se evaluó la adición o no de la enzima exógena Fungamyl 880 I durante la maceración. De esta manera, en la primera y segunda corridas se realizó el remojo con agua y solución de $\mathrm{NaOH}$, respectivamente, y se evaluó la adición de la enzima exógena Fungamyl 800 I durante la maceración en ambas, mientras que en la tercera y cuarta corridas también se efectuó el remojo con agua o solución de $\mathrm{NaOH}$, pero no se incluyó la adición de la enzima durante la maceración. El mosto filtrado obtenido al finalizar la maceración fue puesto a fermentar según los pasos descritos con anterioridad.

\section{Prueba a escala de banco}

Se realizó una prueba de producción de cerveza a escala de banco (25 I) con el fin de estudiar la posibilidad de llevar a cabo el proceso productivo a una escala de producción superior, evaluar la introducción de la etapa de cocción en el proceso productivo, adicionar ambos tipos de lúpulo, y examinar el desempeño operacional de un equipo de maceración novedoso (figura 3 ) bajo las

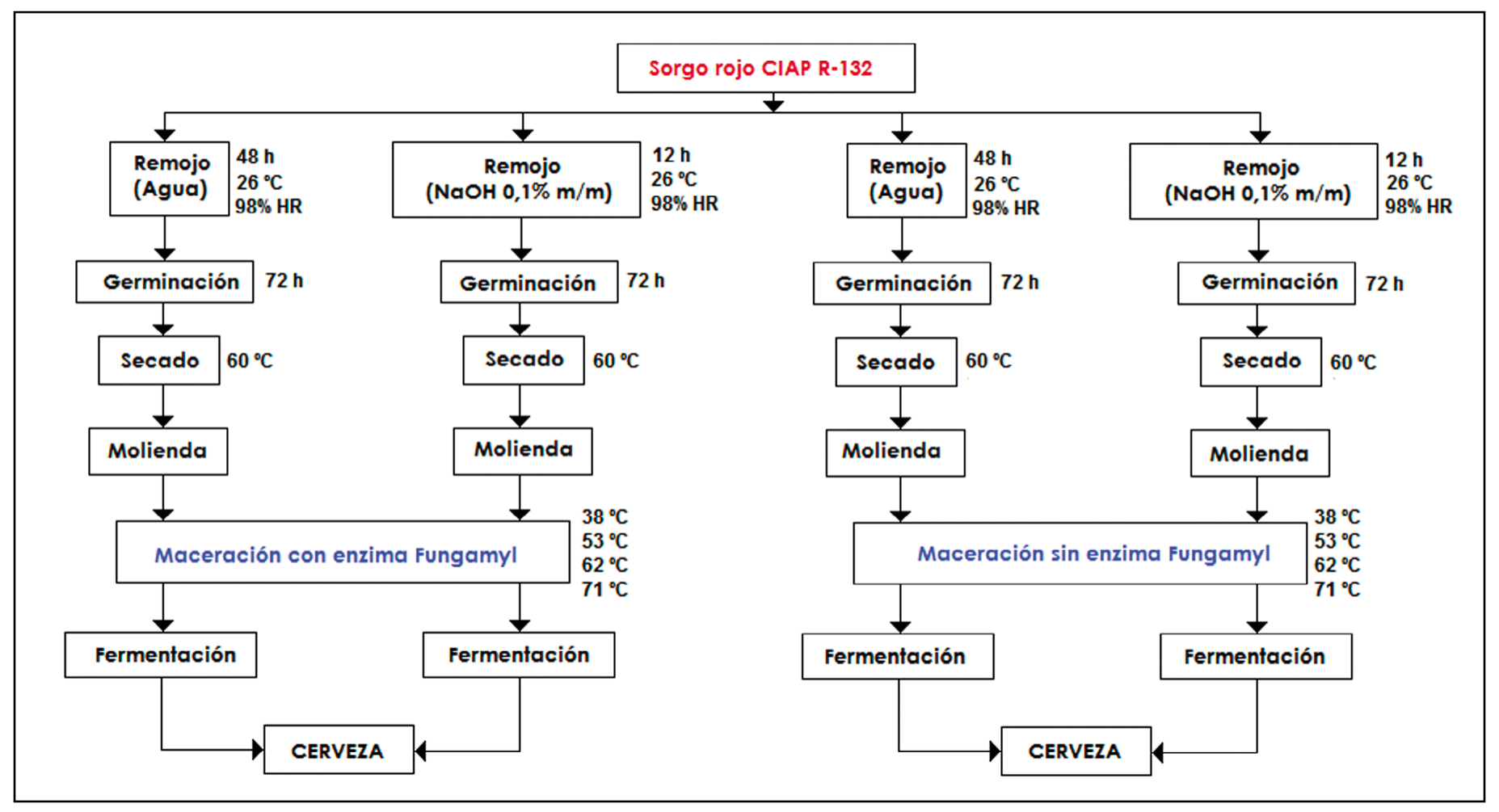

Figura 2. Diseño metodológico elaborado para llevar a cabo el estudio.

Elaboración propia. 
issn 1665-4412, e-issn 2521-9758

Pérez-Sánchez, A., Alfonso-Fernández, H. M., Aragón-Fontes, J. C.,

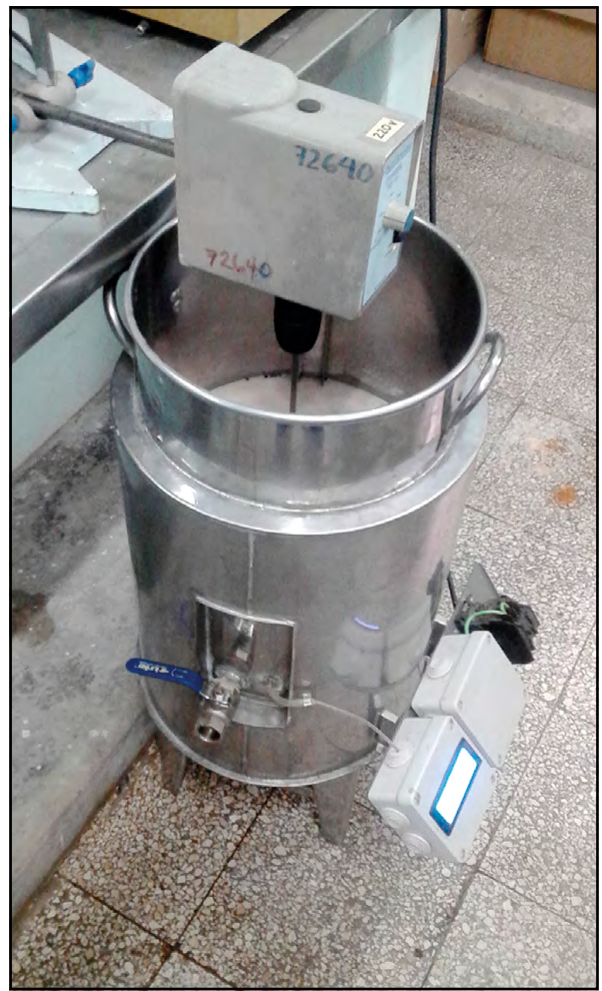

Figura 3. Equipo de maceración empleado en la prueba a escala de banco.

Fotografía del equipo de investigación.

condiciones de operación establecidas a escala de laboratorio.

La prueba productiva consistió en la realización de las operaciones normalmente realizadas a escala de laboratorio, es decir, remojo, germinación, secado, molienda, maceración, filtración primaria, fermentación, filtración secundaria y envasado, pero en este caso incluye la etapa de cocción. Se emplearon $1830 \mathrm{~g}$ de sorgo en total durante este ensayo, el remojo se realizó en solución acuosa de $\mathrm{NaOH}$ al $0.1 \% \mathrm{~m} / \mathrm{m}$, se adicionó la enzima exógena Fungamyl 800 I durante la etapa de maceración, manteniendo las mismas pausas de temperatura utilizadas en los experimentos a escala de laboratorio, mientras que la cocción se realizó a 100 ${ }^{\circ} \mathrm{C}$ de temperatura por $1 \mathrm{~h}$, adicionando lúpulo tanto amargo (11.2 g) como aromático $(2.8 \mathrm{~g})$ durante la misma, además de ácido tánico $(0.7 \mathrm{~g})$.

\section{Determinación experimental de las principales variables evaluadas durante el proceso}

-Sólidos solubles totales (Grados Brix)

Se tomaron $5 \mathrm{ml}$ de la muestra a medir y se filtraron mediante un embudo y papel de filtro. El filtrado obtenido se disgregó posteriormente en el lente de medición del refractómetro $A B B E$, y su lectura de grados Brix ( $\left.{ }^{\circ} \mathrm{BX}\right)$ se registró de forma visual mediante una escala localizada en el propio equipo. Se anotó el ${ }^{\circ} \mathrm{Bx}$, tanto al mosto filtrado obtenido al finalizar la maceración, como a la cerveza obtenida al concluir la fermentación.

- Porcentaje (\%) de humedad de los granos de sorgo

Se colocó una platina de aluminio dentro de una balanza de humedad (ScalTec ${ }^{\circledR}, S M O 01$ ) y se pesó considerando la función de tara. A continuación, se vertieron $10 \mathrm{~g}$ de la muestra a analizar en la platina y se apuntó el porcentaje de humedad de forma automática por la balanza a medida que la muestra se calentaba. Al final se obtuvo la lectura del porcentaje de humedad de los granos de sorgo de forma directa a partir del resultado mostrado en la pantalla digital del equipo.

- $\mathrm{pH}$

Se tomó una muestra de $10 \mathrm{ml}$ y se midió directamente el valor de $\mathrm{pH}$ en un medidor digital de $\mathrm{pH}$ (PHSJ-4A).

Porcentaje (\%) de alcohol o grado alcohólico

El grado alcohólico da la medida de cuánto etanol (en porcentaje en masa) contiene la cerveza obtenida al finalizar la fermentación. $\mathrm{Se}$ determinó mediante el método de refractometría/picnometría (MINAL, 2009), determinando primeramente el extracto real de la muestra.

\section{Extracto original}

Se determinó a partir de los valores de porcentaje de alcohol y extracto real obtenidos por el método de refractometría/picnometría (MINAL, 2009).

- Acidez total

Se deriva de la preparación del mosto, del proceso de fermentación, así como también del grado de carbonatación que presente la cerveza. Se determina por medio de la titulación o neutralización de la muestra con una solución de hidróxido de sodio en presencia del indicador fenolftaleína (MINAL, 2009). Vale destacar que los resultados obtenidos de porcentaje de acidez se expresan como porcentaje de ácido láctico.

\section{Prueba del yodo}

Se le realiza fundamentalmente al mosto obtenido al finalizar la etapa de maceración, con el fin de conocer si ocurrió el desdoblamiento del almidón contenido en los granos de sorgo en 
azúcares fermentables (sacarificación). Se toman $10 \mathrm{ml}$ de muestra del mosto y se le agregan 20 3 gotas de solución de yodo a $25 \%$. Si el color de la muestra se mantiene semejante al color de la solución de yodo (azul oscuro), entonces no ocurrió sacarificación, mientras que si la muestra se transforma desde un color azul oscuro inicial hasta un color semejante al de mosto antes de agregar la solución de yodo, la sacarificación fue positiva.

\section{RESULTADOS}

\section{Humedad de los granos después del remojo}

La humedad de los granos después del remojo presentó un valor promedio de $40.5 \%$ para el remojo en agua, y de $39.8 \%$ para el remojo en solución acuosa de $\mathrm{NaOH} 0.1 \% \mathrm{~m} / \mathrm{m}$.

\section{Curva de secado}

La figura 4 muestra la curva de secado obtenida durante la etapa de secado de los granos de sorgo, a la cual se le ajustó posteriormente una curva polinomial de orden 4.

\section{Porcentaje de germinación}

La tabla 1 muestra el porcentaje de germinación obtenido para cada experimento realizado, en el que se obtuvieron valores entre 69.0 y 80.0 y un promedio de 75.15.

\section{Sólidos solubles totales ( $\left.{ }^{\circ} \mathrm{Bx}\right)$ del mosto al finalizar la maceración}

La tabla 1 expone los resultados de los sólidos

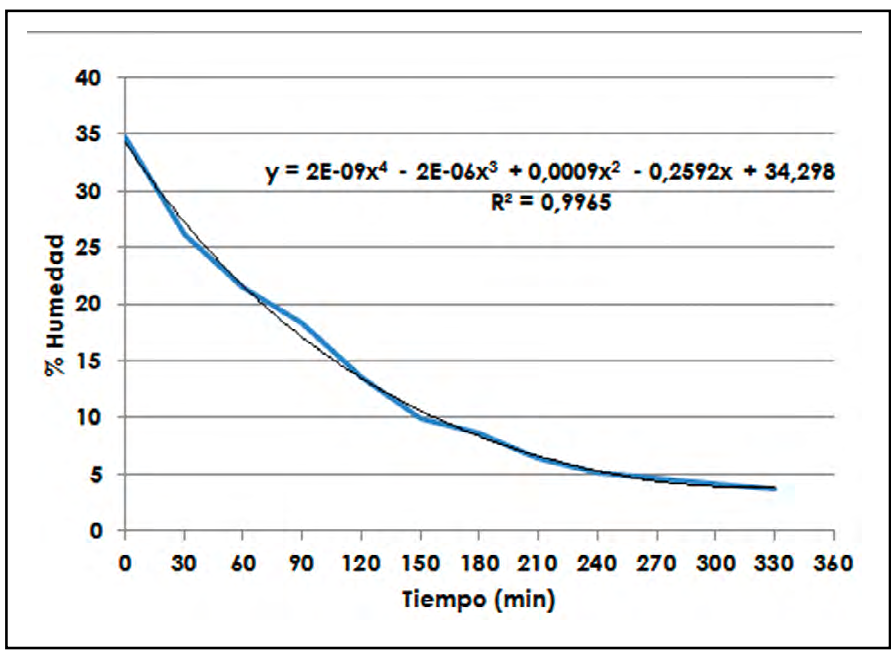

Figura 4. Curva de secado obtenida conteniendo el ajuste polinomial.

Elaboración propia.

solubles totales $\left({ }^{\circ} \mathrm{Bx}\right)$ del mosto obtenido al finalizar la etapa de maceración para ambos experimentos efectuados, tomando en cuenta la adición o no de la enzima exógena Fungamyl 800 I. De forma general se obtuvieron valores de ${ }^{\circ} \mathrm{Bx}$ por encima de 3.5 para todas las corridas consideradas, obteniendo un valor promedio total de 4.41 .

\section{Comportamiento del pH durante la maceración}

El pH del mosto durante la maceración decreció desde un valor inicial promedio de 6.05 hasta un valor final promedio de 5.56 (figura 5) y se mantuvo en todo momento dentro del intervalo recomendable para el proceso (5.5 - 7.0) (Ortega Díaz, 2016), con tendencia a la disminución.

Tabla 1

Resultados de porcentaje de germinación, ${ }^{\circ} \mathrm{Bx}$, porcentaje de alcohol, extracto original y porcentaje de acidez obtenidos en cada experimento efectuado durante la producción de cerveza a escala de laboratorio

\begin{tabular}{|c|c|c|c|c|c|c|c|c|}
\hline \multirow{2}{*}{$\begin{array}{l}\text { Experimento } \\
\text { Corrida }\end{array}$} & \multicolumn{4}{|c|}{ Original } & \multicolumn{4}{|c|}{ Réplica } \\
\hline & 1 & 2 & 3 & 4 & 5 & 6 & 7 & 8 \\
\hline Adición enzima & \multicolumn{2}{|c|}{ Sí } & \multicolumn{2}{|c|}{ No } & \multicolumn{2}{|c|}{ Sí } & \multicolumn{2}{|c|}{ No } \\
\hline Tipo de remojo & Agua & $\mathrm{NaOH}$ & Agua & $\mathrm{NaOH}$ & Agua & $\mathrm{NaOH}$ & Agua & $\mathrm{NaOH}$ \\
\hline \% Germinación & 77.8 & 80.0 & 69.0 & 71.5 & 76.6 & 77.0 & 72.9 & 76.4 \\
\hline${ }^{\circ} \mathrm{Bx}$ & 4.5 & 5.0 & 4.8 & 3.5 & 5.0 & 5.0 & 3.5 & 4.0 \\
\hline \% Alcohol & 2.22 & 1.24 & 1.86 & 0.70 & 0.93 & 1.52 & 1.55 & 0.20 \\
\hline Extracto original & 4.53 & 3.76 & 4.38 & 3.55 & 3,49 & 3.70 & 3.95 & 2.04 \\
\hline \% Acidez & 5.56 & 5.99 & 3.99 & 5.91 & 4.52 & 4.16 & 2.20 & 1.71 \\
\hline Prueba yodo & Sí & Sí & Sí & Sí & Sí & Sí & Sí & Sí \\
\hline
\end{tabular}

Nota: Elaboración propia. 
issn 1665-4412, e-issn 2521-9758

Pérez-Sánchez, A., Alfonso-Fernández,

H. M., Aragón-Fontes, J. C.,

34

\section{Grado alcohólico de la cerveza}

En la tabla 1 se muestran los resultados del porcentaje de alcohol (grado alcohólico) obtenido para la cerveza en cada experimento efectuado. Los resultados mostrados en la misma indican que de las cervezas obtenidas presentó valores fluctuantes y variables, oscilando desde un mínimo de $0.20 \%$ hasta un máximo de $2.22 \%$, con un valor promedio de $1.505 \%$ para el experimento original, y de $1.05 \%$ para la réplica. El porcentaje de alcohol promedio total obtenido fue de $1.28 \%$.

\section{Extracto original para la cerveza}

En cuanto a los valores obtenidos de extracto original (tabla 1), oscilaron entre 2.04 y 4.53 , con un valor promedio total de 3.675 .

\section{Acidez para la cerveza}

La tabla 1 exhibe los resultados del porcentaje de acidez para ambos experimentos. Se obtuvo un promedio de acidez de $5.36 \%$ y de $3.15 \%$ para el experimento original y la réplica, respectivamente, mientras que se obtuvo un valor promedio total de $4.26 \%$.

\section{Resultados obtenidos en la prueba a escala de banco}

La tabla 2 expone los resultados obtenidos en la prueba a escala de banco.

\section{DISCUSIÓN}

Los resultados obtenidos en cuanto a la humedad de los granos de sorgo después del remojo se encuentran ligeramente por debajo del valor recomendado por la bibliografía (French \& McRuer, 1990). En estudios previos se obtuvieron valores de humedad entre 20.34 y $43.81 \%$ (Carvajal, 2014); de $34.4 \%$ (Ortega Díaz, 2016) y entre 20.61 y $41.66 \%$ (Gallardo Aguilar et

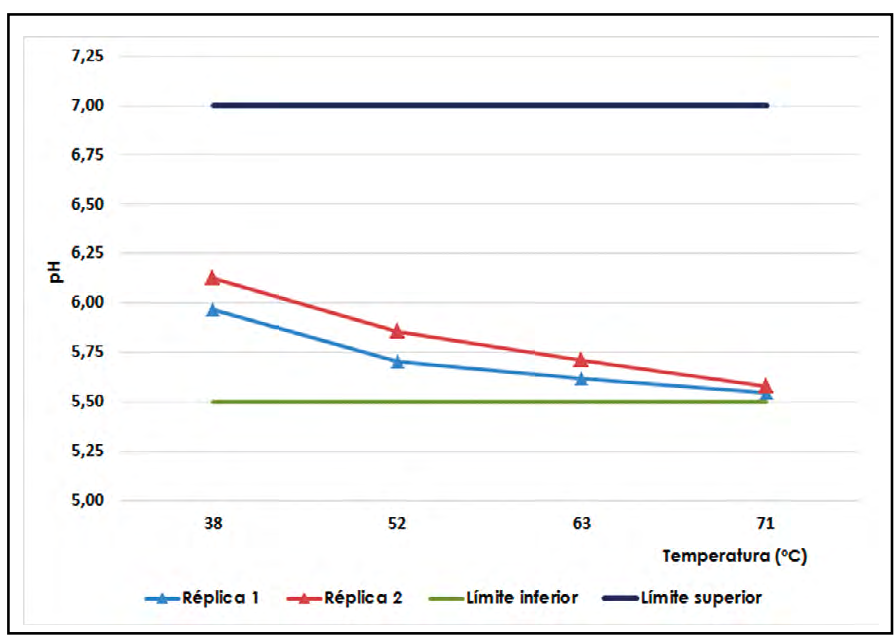

Figura 5. Comportamiento del $\mathrm{pH}$ del mosto durante la maceración.

Elaboración propia.

al., 2018), todos ellos empleando sorgo blanco UDG110.

De acuerdo con los resultados mostrados en la tabla 1, la germinación obtenida puede considerarse satisfactoria, ya que siete de los ocho valores de porcentaje de germinación obtenidos estuvieron por encima de $70 \%$, lo cual está cercano al valor reportado para este tipo de sorgo (Carvajal, 2014). También puede observarse que se obtiene mayor porcentaje de germinación si se emplea la solución de hidróxido de sodio a $0.1 \% \mathrm{~m} / \mathrm{m}$ durante la etapa de remojo, ya que se obtuvo un valor promedio del mismo de $76.225 \%$ empleando esta solución, mientras que el obtenido mediante agua fue de $74.075 \%$. De esta manera se recomienda efectuar el remojo del sorgo rojo CIAP R-132 utilizando la solución de $\mathrm{NaOH}$ a $0.1 \% \mathrm{~m} / \mathrm{m}$, ya que se obtienen resultados superiores del porcentaje de germinación en un menor tiempo (36 h menos), en comparación con los obtenidos

Tabla 2

Principales resultados obtenidos durante la prueba a escala de banco

\begin{tabular}{lc}
\hline Parámetro & Valor \\
\hline Volumen total de mosto al finalizar la maceración & $12.2 \mathrm{I}$ \\
Masa total de afrecho húmedo & $2605 \mathrm{~g}$ \\
oBx del mosto al terminar la maceración & 5.0 \\
Prueba del yodo del mosto después de la maceración & Positivo \\
Volumen total de mosto al finalizar la cocción & $11 \mathrm{~L}$ \\
oBx del mosto al concluir la cocción & 5.1 \\
\% de alcohol del fermento & 0.56 \\
Extracto original de la cerveza & 3.46 \\
Acidez de la cerveza (\%) & 1.29 \\
\hline
\end{tabular}

Nota: Elaboración propia. 
realizando el remojo en agua solamente (Nieblas Morfa et al., 2016). Lo anterior está en concordancia con estudios previos relacionados con este tema (Carvajal, 2014; Díaz Rodríguez, 2014; Ortega Díaz, 2016).

La obtención de un porcentaje de germinación con resultados satisfactorios resulta vital para llevar a cabo adecuadamente las posteriores etapas del proceso productivo (Carvajal, 2014). En estudios previos se obtuvo un porcentaje de germinación de 96\% (Carvajal, 2014), entre 46.42 y $58.69 \%$ (Ortega Díaz, 2016) y entre 3.5 y $88.7 \%$ (Gallardo Aguilar et al., 2018) con sorgo blanco UDG-110.

En cuanto a los valores de ${ }^{\circ} \mathrm{Bx}$ obtenidos, se obtuvo un valor superior en las corridas que utilizaron la enzima Fungamyl 800 । durante la maceración (promedio de 4.875), en comparación con las que no (promedio de 3.95). Se puede concluir que existe una mayor sacarificación y rendimiento de ${ }^{\circ} \mathrm{Bx}$ superior si se emplea dicha enzima en esa fase. En estudios anteriores se obtuvo un valor promedio de 'Bx entre 3.5 y 7.0 (Gallardo Aguilar et al., 2013), de 7.5 (Carvajal, 2014), y de 4.2 (Ortega Díaz, 2016) al finalizar la etapa de maceración, empleando en todas ellas sorgo blanco UDG-110.

El grado alcohólico obtenido en todos los experimentos siempre fue inferior del porcentaje de alcohol mínimo establecido para la cerveza Tínima de tipo ligera, que es de 3.0 (MINAL, 2009), mientras que con excepción de la corrida 1 , estos se encuentran también por debajo del rango promedio definido por la bibliografía consultada (Carvajal, 2014) en donde se establece un rango promedio de grado alcohólico entre 2.0 y $4.5 \%$ para cervezas obtenidas íntegramente a partir de sorgo. Lo anterior puede deberse, fundamentalmente, a la baja concentración de azúcares fermentables presentes en el mosto antes de la fermentación, ya que en este estudio no se agrega azúcar (crudo o refino) ni otros licores o aditivos ricos en azúcares al mosto antes de ser fermentado. A pesar de estos resultados, se puede concluir que en todas las corridas se obtuvo cerveza conteniendo alcohol, aunque no con las concentraciones establecidas por la bibliografía. En estudios precedentes relacionados con la elaboración de cerveza a partir de sorgo blanco UDG-110 se obtuvieron valores de porcentaje de alcohol entre 1.68 y 3.24 (Gallardo Aguilar et al., 2013), entre 5.63 y 15.16 (Carvajal, 2014) y entre 1.00 y 4.88 (Ortega Díaz, 2016).
Con respecto a los valores obtenidos de extracto original mostrados en la tabla 1 , se puede observar que todas las corridas presentaron valores de extracto original por debajo del límite mínimo requerido para la cerveza Tínima (7.5) (MINAL, 2009), mientras que no se reportan valores de este parámetro en la bibliografía consultada (Carvajal, 2014; Díaz Rodríguez, 2014; Gallardo Aguilar et al., 2013; Nieblas Morfa et al., 2016; Ortega Díaz, 2016).

La acidez promedio total obtenida (4.26\%) se encuentra encima del valor máximo requerido para la cerveza Tínima, que es de $3.50 \%$, aunque se debe notar que los experimentos 7 y 8 presentaron valores por debajo de este límite máximo. Esto se debe probablemente a la acción fermentativa predominante de bacterias de ácido láctico, fundamentalmente Lactobacillus fermentum, Lactobacillus buchneri y/o Lactobacillus divergens, cuya presencia ha sido reportada (Lyumugabe, Kamaliza, Bajyana, \& Thonart, 2010) como un suceso normal y típico durante la etapa de fermentación de cerveza a partir de sorgo. Se ha indicado (Kayodé, Adegbidi, Hounhouigan, Linnemann, \& Nout, 2005; Maoura \& Pourquie, 2009) que las cervezas obtenidas a partir de sorgo constituyen ejemplos característicos de la fermentación láctica seguida de la alcohólica en donde las bacterias de ácido láctico (BAL), y luego las levaduras, juegan el papel dominante. Se ha comprobado que las BAL crean un ambiente ácido favorable para la proliferación de las levaduras. Estas levaduras, a su vez, producen vitaminas e incrementan los aminoácidos, que ayudan al crecimiento de las BAL. Debido a su elevado crecimiento, las bacterias lácticas usualmente dominan en las etapas tempranas de la fermentación, mientras se establece una relación simbiótica, la cual explica la presencia simultánea de BAL y levaduras durante la fermentación (Lyumugabe et al., 2010).

La posible aparición de estas y otras bacterias durante la fermentación pudo ocurrir debido a la no realización de la etapa de cocción del mosto obtenido al finalizar la maceración, ya que como etapa fundamental previa al proceso de fermentación se logra reducir la carga bacteriana (esterilización) del mosto, lo que previene la acción fermentativa de microorganismos ajenos al proceso de fermentación alcohólica, que pueden transmitirle sabores extraños a la cerveza debido a su actividad metabólica, además de incrementar los valores de ciertos parámetros fisicoquímicos importantes 
a controlar para la cerveza, como la acidez. En estudios precedentes se han obtenido valores de la misma en cervezas producidas a partir de sorgo entre 0.09 y $0.36 \%$ (Carvajal, 2014), y entre 0.27 y $1.92 \%$ (Ortega Díaz, 2016) utilizando sorgo blanco UDG-1 10. También entre 1.52 y $1.68 \%$ mezclando sorgo blanco UDG-110 con cebada malteada (Nieblas Morfa et al., 2016) y entre 1.52 y $1.71 \%$, mezclando sorgo rojo CIAP R-132 con cebada malteada (Nieblas Morfa et al., 2016).

De acuerdo con los resultados de la tabla 2, tanto el porcentaje de alcohol como el extracto original de la cerveza obtenida a escala de banco, tienen valores inferiores a los reportados por la bibliografía y para la cerveza Tínima, respectivamente, lo cual puede deberse a la baja concentración de azúcares en el mosto previo a la fermentación, ya que únicamente se metabolizan aquellos azúcares fermentables extraídos del sorgo durante la etapa de maceración, pues no se agregan cantidades adicionales de sacarosa $u$ otros aditivos o licores ricos en azúcares.

Por otra parte, el porcentaje de acidez se encuentra dentro de los límites establecidos para la cerveza Tínima (1.12-3.50\%) (MINAL, 2009), lo cual puede ser debido a la baja presencia de microorganismos contaminantes productores de ácido láctico y otros compuestos ácidos (o lo que es lo mismo, generadores de acidez) en el mosto como consecuencia de la realización de un proceso de cocción previo a la etapa de fermentación, el cual constituye un método efectivo para esterilizar el mosto antes de ser fermentado. Considerando estos resultados, se recomienda efectuar estudios posteriores a escala de laboratorio en donde se incluya la etapa de cocción en el proceso productivo.
CONCLUSIONES

- El remojo del sorgo rojo en solución de $\mathrm{NaOH}$ a $0.1 \% \mathrm{~m} / \mathrm{m}$ permite obtener, en un menor tiempo, resultados del porcentaje de germinación superiores a los obtenidos mediante remojo en agua.

- El comportamiento del pH durante la maceración se mantiene dentro del intervalo deseado (5.57.0), con tendencia a la disminución.

- Se obtienen mayores valores de ${ }^{\circ} \mathrm{Bx}$ durante la maceración al emplear la enzima exógena Fungamyl $800 \mathrm{l}$.

- Se obtuvo un valor promedio de ${ }^{\circ}$ Bx igual a 4.41 al finalizar la etapa de maceración.

- Se obtuvo un valor promedio de porcentaje de alcohol de 1.28\%, por debajo del valor mínimo establecido para la cerveza Tínima y en la bibliografía consultada.

- Se alcanzó un valor promedio de extracto original de 3.68, por debajo del valor mínimo establecido para la cerveza Tínima.

- Se obtuvo un promedio de porcentaje de acidez de $4.26 \%$, superior a los valores reportados por la literatura y para la cerveza Tínima.

- La cerveza obtenida en la prueba a escala de banco presentó un porcentaje de alcohol de 0.56, valor de extracto original de 3.46 y acidez de 1.29 .

- Se recomienda realizar la etapa de remojo en solución de $\mathrm{NaOH} 0.1 \% \mathrm{~m} / \mathrm{m}$, llevar a cabo la etapa de cocción en el proceso productivo, añadir sacarosa o compuestos ricos en azúcares fermentables al mosto antes de la fermentación y agregar la enzima exógena Fungamyl 800 । durante el proceso de maceración. 


\section{REFERENCIAS}

- Bernal Negrete, L. G., Pérez Rodríguez, G. I., \& Delgado Morales, R. (2015). Transformación e innovación de granos: El sorgo para la elaboración de cerveza artesanal. En Memorias del $20^{\circ}$ Encuentro Nacional sobre Desarrollo Regional en México, Cuernavaca, Morelos, México.

- Carvajal, N. (2014). Perfeccionamiento del proceso de producción de cerveza a partir de malta de sorgo (Trabajo de Diploma, Universidad Central "Marta Abreu" de Las Villas Villa Clara, Cuba). Recuperada de http://dspace.uclv.edu. cu/handle/123456789/158

- Chaviano Marañón, M. (2005). El sorgo: Contribución al desarrollo sostenible y ecológico de la producción popular de arroz. Agricultura Orgánica, 1 (1), 8-11.

- Díaz Rodríguez, Y. (2014). Perfeccionamiento del proceso de malteado de sorgo para la producción de maltinas para enfermos celíacos (Trabajo de Diploma, Universidad Central "Marta Abreu" de Las Villas Villa Clara, Cuba). Recuperada de http://dspace.uclv.edu.cu/handle/123456789/194

- French, B. J., \& McRuer, G. R. (1990). Malt quality as affected by various steep aeration regimes. Technical Quarterly Master Brewers Association of the Americas, 27(1), 10-14.

- Gallardo Aguilar, I., Boffill Rodríguez, Y., Ozuna, Y., Gómez, O., Pérez, M., \& Saucedo Castillo, O. (2013). Producción de bebidas usando sorgo malteado como materia prima para enfermos celíacos. Avances en Ciencias e Ingeniería, 4 (1), 6174.

- Gallardo Aguilar, I., Boffill Rodríguez, Y., Rega López, L., Pino Hurtado, M. S., Rodríguez Padrón, Y., \& Pérez Pentón, M. (2018). Perfeccionamiento del proceso de malteado de sorgo UDG110 en la elaboración de bebidas para enfermos celíacos. Revista Centro Azúcar, 45(2), 46-58.

- Kayodé, P., Adegbidi, A., Hounhouigan, J. D., Linnemann, A. R., \& Nout, R. (2005). Quality of farmers' varieties of sorghum and derived foods as perceived by consumers in Benin. Ecology of Food and Nutrition, 44(4), 271-294.

- Lyumugabe, F., Gros, J., Nzungize, J., Bajyana, E., \& Thonart, P. (2012). Characteristics of African traditional beers brewed with sorghum malt: A review. Biotechnology, Agronomy, Society and Environment, 16(4), 509-530.
- Lyumugabe, F., Kamaliza, G., Bajyana, E., \& Thonart, P. H. (2010). Microbiological and physico-chemical characteristic of Rwandese traditional beer "Ikigage". African Journal of Biotechnology, 9(27), 4241-4246.

- MINAL. (2009). Manual de Métodos de Ensayo. Camagüey: Laboratorio Central- Empresa Cervecería Tínima-Ministerio de la Industria Alimenticia.

- Nanadoum, N., \& Pourquie, J. (2009). 5-Sorghum beer: Production, nutritional value and impact upon human health. En Beer in Health and Diseases Prevention (pp. 53-60). US: Elsevier Academic Press.

- Nieblas Morfa, C., Gallardo Aguilar, I., Rodríguez Rodríguez, L., Carvajal Mena, N., González Chávez, J. F., \& Pérez Pentón, M. (2016). Obtención de bebidas y otros productos alimenticios a partir de dos variedades de sorgo. Revista Centro Azúcar, 43(3), 66-77.

- Ortega Díaz, M. (2016). Producción de cerveza empleando integralmente el grano de sorgo (Trabajo de Diploma, Universidad Central "Marta Abreu" de Las Villas Villa Clara, Cuba).

- Ramatoulaye, F., Mady, C., Fallou, S., Amadou, K., Cyril, D., \& Massamba, D. (2016). Production and use sorghum: A literature review. Journal of Nutritional Health \& Food Science, 4(1), 1-4. doi: 10.15226/jnhfs.2016.00157

- Ratnavathi, C. V., \& Chavan, U. D. (2016). Malting and brewing of sorghum. En C.V. Ratnavathi, J.V. Patil, \& U. D. Chavan (Eds.), Sorghum biochemistry. An industrial perspective (pp. 63106). Oxford: Academic Press.

- Rodríguez Rodríguez, L., Gallardo Aguilar, I., Nieblas Morfa, C., Medina Macola, J., \& Ortiz Fernández, W. (2015). Obtención de jarabes dextrinizados mediante hidrólisis enzimática del almidón de sorgo. Revista Centro Azúcar, 42(4), 49-58.

- Rodríguez Rodríguez, L., Gallardo Aguilar, I., Nieblas Morfa, C., \& Ortiz Fernández, W. (2015). Evaluación de dos variedades de sorgo para la obtención de almidón. Revista Centro Azúcar, 42(1), 88-95. 